\title{
The Northern Iroquoian nominalizer and lexical categories
}

\author{
MICHAEL BARRIE \\ Sogang University \\ mikebarrie@sogang.ac.kr \\ and \\ SIHUN JUNG \\ Sogang University \\ sihun.jung@gmail.com
}

\begin{abstract}
In Northern Iroquoian languages, a nominalizer (NLZR) is typically required to transform a verb into a noun, either for noun incorporation or to create a full DP. In some cases, the nominalizer is required only for noun incorporation and not for the formation of a DP. Interestingly, the converse is never found. That is, there are no lexical roots that require the nominalizer for the formation of a DP, but not for noun incorporation. With this asymmetry in mind, we examine the categorial properties of roots in Northern Iroquoian. We discuss three common theories of the categorization of roots: (i) the traditional theory, in which all roots are specified as nouns or verbs (or adjectives for languages that have this category), (ii) the Bare Root Hypothesis, in which all roots are acategorial, and (iii), the Roots as Nouns Hypothesis, in which all roots are nouns. We show that the Northern Iroquoian facts are not amenable to any of these theories. We propose instead that some roots in Northern Iroquoian are categorially specified (some as nouns, some as verbs), while others are truly bare.
\end{abstract}

Keywords: roots, categorization, Northern Iroquoian

\section{Résumé}

Dans les langues iroquoiennes du nord, un nominalisateur (NLZR) est généralement requis pour transformer un verbe en un nom, que ce soit pour l'incorporation nominale, ou pour créer un

We wish to thank the audience at WSCLA23 for helpful feedback and suggestions. All errors are our own. This work was supported by the Global Research Network program through the Ministry of Education of the Republic of Korea and the National Research Foundation of Korea (NRF-2017S1A2A2039972). 
DP complet. Dans certains cas, le nominalisateur est nécessaire seulement pour l'incorporation nominale et est absent lors de la formation d'un DP complet. Le cas inverse ne s'observe pas, c'est-à-dire qu'il n'existe pas dans le lexique des radicaux qui nécessitent un nominalisateur pour la formation d'un DP, mais qui n'en nécessitent pas pour l'incorporation nominale. C'est en partant de cette asymétrie que nous abordons le problème de la nature des radicaux dans l'iroquoien du nord. Nous considérons trois théories répandues sur le sujet de la catégorisation des radicaux : (i) la théorie traditionnelle, dans laquelle tous les radicaux sont spécifiés, soit en tant que nom, soit en tant que verbe (ou en tant qu'adjectif pour les langues avec cette catégorie), (ii) l'hypothèse des radicaux nus, dans laquelle tous les radicaux sont analysés comme étant dépourvus de catégorie et (iii), l'hypothèse des radicaux en tant que noms, une théorie dans laquelle tous les radicaux sont des noms. Nous montrons que les faits observés dans l'iroquoien du nord ont du mal à trouver une explication au sein de chacune de ces théories. Nous proposons plutôt qu'il existe certains radicaux dans ces langues qui ont une catégorie assignée - soit nom, soit verbe - tandis que d'autres sont véritablement nus, et donc n'ont pas de catégorie grammaticale inhérente.

Mots-clés: radicaux, catégorisation, iroquoien du nord

\section{INTRODUCTION}

Lexical roots are traditionally classified as verbs, nouns or, for languages that have them, adjectives (see Baker 2003 for a historical overview). ${ }^{1}$ This traditional understanding of lexical categories was formalized in Chomsky's (1970) analysis of nominalizations. There has been no dearth of discussion on the nature and category of roots since Chomsky's original proposal (Marantz 1997, Caramazza and Shapiro 2004, Borer 2005, Wiltschko 2005, Kayne 2009, Panagiotidis 2011, Chung 2012, Haugen and Siddiqi 2013, Moulton 2014). In this article, we consider the nature of lexical categories in light of the asymmetric behaviour of nominalizers in Northern Iroquoian languages. We show that the asymmetric behaviour of the nominalizer can be explained if we assume that some (but not all) roots are inherently categorized. This proposal departs from the Borer-Chomsky Hypothesis that roots have no grammatical or categorial information (Borer 1984, Marantz 2001, Borer 2005). Such a retreat has also been proposed by Moulton (2014), who argues that certain roots encode event information. To be clear, we propose here that while some roots are bare, some are categorially specified as nouns or verbs.

The empirical foundation of our argument lies in the following generalization, well known among Iroquoianists (Lounsbury 1949, 1953; Abbott 2000, Chafe

\footnotetext{
${ }^{1}$ The following abbreviations are used in this article: AG: agent; CAUS: causative; DU: dual; EPEN: epenthetic vowel; EXCL: exclusive; F: feminine; FACT: factual;FUT: future; HAB: habitual; INCH: inchoative; JoIN: joiner vowel (an epenthetic vowel that occurs between incorporated noun and verb stem); M: masculine; NE: specificity marker; NFS: noun forming suffix; NI: noun incorporation; NLZR: nominalizer; NPREF: noun prefix; NT: neuter; PAT: patient; PUNC: punctual; REP: repetitive; SG: singular; SRFL: semi-reflexive; STAT: stative.
} 
2014, Barrie 2015, Michelson et al. 2016, Woodbury 2018), but seldom discussed in the generative literature. Northern Iroquoian languages have a nominalizer that turns a verb into a noun. When this morpheme is added to what is traditionally thought of as a verbal root, the resultant form can be used to form a noun, or it can undergo noun incorporation (NI). Noun roots, of course, do not require a nominalizer. There is a small number of roots that require the nominalizer in order to undergo noun incorporation, but not for forming a noun. The inverse situation, in which a nominalizer is needed for forming a noun but not for noun incorporation, is not attested. This asymmetry is the basis of our discussion.

The remainder of the article is structured as follows. Section 2 discusses the background on theories of lexical categories, including the traditional notion of categories (as formalized in Chomsky 1970, but going back to at least Pānini), acategorial roots (Borer 1984, Marantz 1997, Borer 2005), and roots as nouns (Kayne 2009). Section 3 presents relevant aspects of the grammar of Northern Iroquoian languages, including nominal and verbal structure. Section 4 discusses how the previous theories of lexical categories just discussed would handle the Northern Iroquoian facts. Section 5 presents our analysis, pointing out various shortcomings, and section 6 concludes the article, suggesting an avenue for further research.

\section{BACKGROUND}

The traditional notion of the category of roots holds that they are inherently specified for category ( $\operatorname{dog}$ is a noun; run is a verb). This is discussed in Chomsky (1970) and formalized in Chomsky and Lasnik (1977: 430), but of course is found in traditional grammars throughout history going back, as mentioned, to at least Pānini. Chomsky and Lasnik proposed bivalent categorial features as in (1).

(1) a. Noun: $[+\mathrm{N},-\mathrm{V}]$

b. Verb: $[-\mathrm{N},+\mathrm{V}]$

c. Adj: $[+\mathrm{N},-\mathrm{V}]$

d. Preposition: $[-\mathrm{N},-\mathrm{V}]$

Many traditional grammatical descriptions and analyses still assume that roots are always categorially specified.

A well-known competing hypothesis for the nature of roots is to assume that all roots are categorially unspecified (Borer 1984, 2005; Marantz 1997; Panagiotidis 2011). For convenience we refer to this as the Bare Roots Hypothesis. Support for this hypothesis comes from the observation that the same root can be a noun, verb or adjective in many cases: The car is red. I like the colour red. John reddened the icing. Note that in this case an affix appears on the verb redden, but the point is that the lexical root contained inside this verb is a category neutral root. Categorizers are typically identified as $v, n$, and $a$. 
The final hypothesis we investigate has not gained as much widespread recognition, so we describe it in more detail here. In this proposal, all roots are nouns (Kayne 2009). For convenience we refer to this as the Roots as Nouns Hypothesis. Verbs, then, are typically derived from a nominal root plus a verbalizer; however, Kayne proposes that a large number of verbs are likely functional heads. Under Kayne's proposal, the nominal root undergoes SELF-MERGE forming a phrase. ${ }^{2}$ This NP can then participate in the formation of a DP, or it can merge with a light verb to form what is normally perceived as a verb (possibly by conflation in the sense of Hale and Keyser 2002). These two possibilities are illustrated here. Note, though, that while Kayne suggests that verbs are either light verbs or involve conflation, he does not give a full account of how verbs are formed. The structures below are an extrapolation of his discussion. ${ }^{3}$

(2) a.

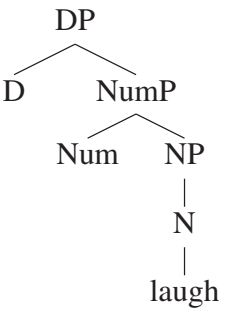

b. $\quad v \mathrm{P}$

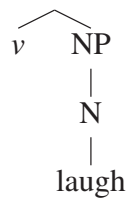

Northern Iroquoian languages are spoken in east-central North America on the border between Canada and the US. Northern Iroquoian languages are highly polysynthetic and exhibit noun incorporation (Lounsbury 1949, 1953; Mithun 1979; Baker 1996; Abbott 2000; Barrie 2015; Michelson 2016; Michelson et al. 2016; Woodbury 2018). Extant Northern Iroquoian languages include Onondaga, Oneida, Cayuga, Seneca, Mohawk and Tuscarora. Examples will be drawn from the first four of these.

The Iroquoian family has two branches: Southern Iroquoian (spoken in Oklahoma and North Carolina), and Northern Iroquoian (spoken in Ontario, New York State and Minnesota). This article deals only with Northern Iroquoian languages. Northern Iroquoian languages are highly polysynthetic and exhibit complex agreement with both the subject and the object (Lounsbury 1949, Baker 1985). We present the classification of the extant Iroquoian languages here (Julian 2010). The names of the languages are given in italics.

\footnotetext{
${ }^{2}$ Merge, of course, typically involves combining two distinct syntactic objects to form a single syntactic object. Kayne notes that nothing precludes the possibility of Merge selecting the same object twice, effectively giving a unary branching structure.

${ }^{3}$ Specifically, Kayne suggests that the NP in (2b) incorporates into the null $v$. He notes that verbs, at least in colloquial English, can be phrasal as in Don't Monday-morning-quarterback him so much (his footnote 21). A reviewer also points out that a number of other researchers have independently proposed that phrasal material can appear inside what is traditionally taken to be a word (Harley 2009, Sato 2010, Compton 2013).
} 


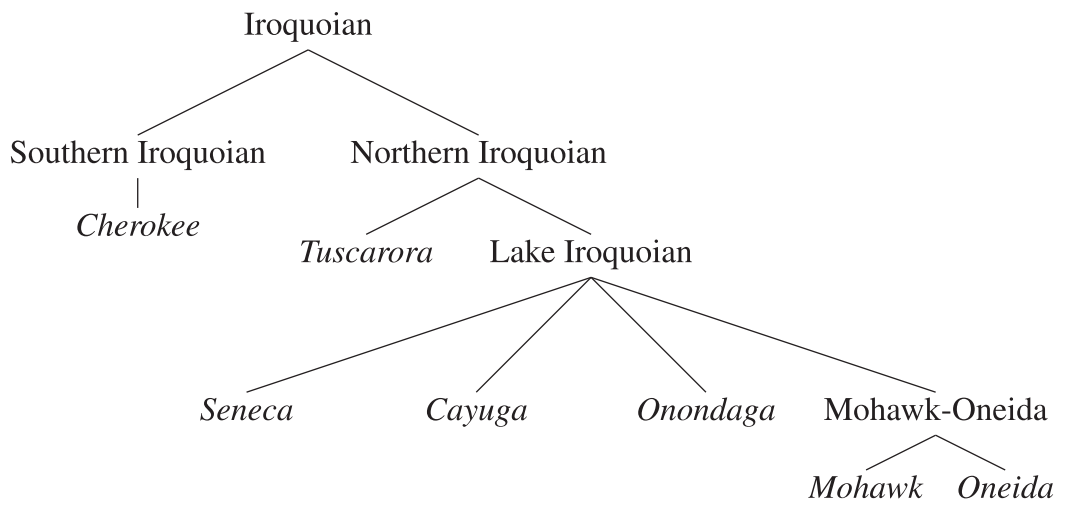

In the next section, we describe aspects of verbal and nominal structure as well as noun incorporation in Northern Iroquoian.

\section{Properties OF LEXICAL CATEgories IN NORTHERN IROQUOIAN}

This section discusses the relevant properties of nominal and verbal structure in Northern Iroquoian (Lounsbury 1949, 1953) as well as the basic properties of noun incorporation (Woodbury 1975a,b). We discuss in detail the asymmetry described in the introduction, concentrating on the requirement for a nominalizer with various kinds of roots. First, however, we provide some background on Northern Iroquoian.

Traditionally, roots in Northern Iroquoian languages are described as either nominal or verbal. Nominal roots appear in nouns and can be incorporated as described in the previous section. Verbal roots require a nominalizer in order to be used as nouns or to undergo noun incorporation. In the following discussion we refer to the overt nominalizer in Northern Iroquoian as the "overt NLZR", to match the interlinear gloss. When needed, a hypothetical null nominalizer will be referred to as "null $n$ ". A generic term for any nominalizer will simply be $n$. As mentioned in the introduction, there are three kinds of roots that can be described with respect to the use of the nominalizer. Traditional nouns never require a nominalizer for NI or for forming a full DP. Traditional verbs typically do require a nominalizer both for NI and for forming a full DP. What is not much discussed is the third kind of roots mentioned, in which the nominalizer is required for NI only. We commence with a basic description of nominal and verbal structure, then present several examples of these three types of roots. Hereafter, we use the term "traditional noun root" and "traditional verb root" to refer to the traditional notions of these two concepts as described in the Iroquoianist literature.

\subsection{Nominal structure}

Regular full nominals in Northern Iroquoian typically consist of a lexical root, a nominal prefix and a nominal suffix. Consider the Onondaga examples in (3). ${ }^{4}$

\footnotetext{
${ }^{4}$ We use four-line glossing, as the morphophonology often obscures the underlying morphological structure.
} 
(3) a. oyọ́:da?

[Onondaga]

o-yǫt-a?

NPREF-beak-NFS

'beak'

Woodbury (2003: 937)

b. ganákda?

ka-nakt-a?

NPREF-bed-NFS

'bed'

Woodbury (2003: 677)

The suffix (NFS) is often arbitrary or reduced to a single form. In Onondaga, however, it typically indicates the noun class: human or non-human (Woodbury 2003). The noun prefix (NPREF) is also typically arbitrary. In Onondaga non-human nouns it indicates noun class (natural or man-made, with some exceptions). In Seneca one prefix is historically older, so more newly coined words tend to have the newer prefix. One can easily see the link between more newly coined words and man-made items, but whether there is a connection between these two properties in Onondaga and Seneca, respectively, requires further investigation. As the structure of nouns is well established and has been illustrated in numerous previous sources, we have given just two examples here.

Next, what are traditionally described as verbal roots (in an ontological sense) are nominalized with an overt nominalizer. In the Cayuga example shown in (4), the nominalizer appears between the root and the noun forming suffix. Again, this has been amply illustrated in the literature.

(4) gahyádọhsra?

ka-hyato-hsr-a?

NPREF-write-NLZR-NFS

'paper'

[Cayuga]

Froman et al. (2002: 224)

\subsection{Verbal structure}

As in many polysynthetic languages, the verbal structure of Northern Iroquoian languages can be complex. Traditional descriptions of the verbal complex can be found in Lounsbury (1949, 1953), Mithun and Henry (1984), Abbott (2000), Barrie (2015), Michelson et al. (2016), Woodbury (2018), as well as the dictionaries referenced throughout this article. All verbs require a pronominal prefix indicating the core discourse participants, a verb root, and an aspectual suffix, as illustrated in the Onondaga example in (5). In addition to the agreement prefix and the aspectual suffix, this form also contains a factual mood prefix.

(5) wa?hahninú?

wa?-ha-hninu-?

[Onondaga]

FACT-3sG.M.AG-buy-PUNC

'He bought it.'

(adapted from Woodbury 1975b: 13)

\subsection{Noun incorporation}

Northern Iroquoian is well-known for noun incorporation (Woodbury 1975a,b; Mithun 1984; Baker 1988). While the details of noun incorporation differ from 
one language to the next (Barrie and Mathieu 2016), in Northern Iroquoian, noun incorporation is typically formed by the incorporation of a nominal root into the verbal complex. The nominal prefix and suffix just described are absent. A typical example from Onondaga is given in (6); note that the orthography has been updated to conform to standard Iroquoianist practice.

(6) Onondaga

Woodbury (1975b: 13)

a. wa?-ha-hninu-? ne? o-yękw-a?

FACT-3SG.M.AG-buy-PUNC NE 3SG.NT-tobacco-NFS

'He bought the tobacco.'

b. wa?-ha-yękw-a-hninu-?

FACT-3SG.M.AG-tobacco-JOIN-buy-PUNC

'He bought tobacco.'

\subsection{Three kinds of roots}

As mentioned in the introduction, there are three kinds of roots with respect to DP structure and noun incorporation: (i) roots such as tobacco, which require a nominalizer neither for NI nor for forming a full DP, (ii) roots such as write, which require a nominalizer both for NI and to form a full DP, and (iii) roots such as friend, which require a nominalizer for NI only. What is absent is the fourth logical possibility - roots that require a nominalizer to form a full DP, but not for NI. We discuss these three kinds of roots in turn. As this section provides the core empirical basis for our discussion, we provide numerous examples, especially of the third type.

\subsubsection{Roots that never require a nominalizer}

An example of a root that never requires a nominalizer was given in (6). In the discussions below, these will often be referred to as tobacco-type roots. They typically correspond to traditional noun roots. Some additional examples from other Northern Iroquoian languages are given in (7) and (8).

(7) a. gPanigoha?

ka-2nikọh-a?

NPREF-mind-NFS

'the mind'

(adapted from Froman et al. 2002: 381)

b. ęhshe?nigọhọ́:ni?

ę-hshe-Pnikọh-ǫni-?

FACT-2SG.AG:3SG.F.PAT-mind-make-PUNC

'You will persuade someone.'

(adapted from Dyck et al. 2014: 46)

(8) a. kanúhsa?

ka-nuhs-a?

NPREF-house-NFS

'house'

(adapted from Michelson and Doxtator 2002: 602)

b. wa?katnuhsahni:nú:

wa?-k-at -nuhs-a-hninu-؛

FACT-1SG.AG-SRFL-house-JOIN-buy-PUNC

'I sold a house.'

(adapted from Michelson and Doxtator 2002: 179) 


\subsubsection{Roots that require a nominalizer for both NI and DP}

When a verbal root is used to form a DP or is incorporated, it typically appears with a nominalizer (Woodbury 2003, Dyck et al. 2014), as shown in (9) and (10). In the discussion below, these examples are often referred to as write-type roots. These roots typically correspond to traditional verbs.

(9) a. ehyá:dǫh

e-hyato-h

[Cayuga]

3sG.F.AG-write-HAB

'She writes.'

(Froman et al. 2002: 375)

b. gahyádohsra?

ka-hyato-hsr-a?

NPREF-write-NLZR-NFS

'paper'

(Froman et al. 2002: 224)

c. syadǫhsraędi?

s-hyatǫ-hsr-yętei-?

2SG.AG-write-NLZR-know-HAB

'You are smart.'

(Froman et al. 2002: 300)

('know-paper' is an idiom for 'be smart')

(10) a. ada?dítshä?

[Onondaga]

$\varnothing$-at-a?ti-tshR-a?

NPREF-SRFL-lean-NLZR-NFS

'cane/crutches'

(Woodbury 2003: 102)

b. hoda?ditsheda?

ho-at-a?ti-tshR-ot-a?

3SG.M.PAT-SRFL-lean-NZRL-stand.upright/have-STAT

'He is using a cane.'

(Woodbury 2003: 102)

\subsubsection{Roots that require the nominalizer for NI only}

There are a handful of roots with which the nominalizer is required only when it is incorporated and not when it appears in a full DP. Consider the Onondaga examples in (11) and (12). In the second of these examples, the root is a borrowing. In this particular example, the fact that the root is borrowed does not affect the rest of the morphological structure. Unlike some loan words which have not been fully integrated into the language (such as kháfe 'coffee'), the borrowed form for 'soldier' has been fully integrated into Onondaga. Note the significant difference in the phonological form (as compared to similarity of the borrowed form for 'coffee'). Most importantly, the borrowed root hsota:ho 'soldier' requires the same nominal morphology that native roots require, whereas khófe 'coffee' remains bare. In other words, fully integrated roots like hsota:ho 'soldier' exhibit the same properties as native roots, but more recently borrowed roots behave slightly differently, and, unsurprisingly, do not have the same properties as native roots or 
fully integrated borrowed roots. We leave the more recently borrowed roots for future research. ${ }^{5}$

(11) a. Qgátci?

[Onondaga]

yǫk-atci-?

1DU.PAT-friend-NFS

'my friend'

(Woodbury 2003: 255)

b. hatsihsắ:yęk

ha-atci-hsR-a-yę-k

3sG.M.AG-friend-NLZR-JOIN-know.how-HAB

'He knows how to be friends.'

(Woodbury 2003: 255)

(12) a. hahsodá:hoh

ha-hsota:ho-h

3sG.M.AG-Soldier-NFS

'male soldier'

(Woodbury 2003: 559)

b. wa?hatshoda:Ptshę:nya?

wa?-ha-at-hsota:-?tshR-ǫny-a?

FACT-3SG.M.AG-SRFL-Soldier-NLZR-make-PUNC

'He enlisted.' (lit: He made himself a soldier.)

(Woodbury 2003: 303)

In the Cayuga example in (13b), the derived verbal form has been re-nominalized. Nevertheless, to initially undergo noun incorporation with the verb /ony/ ('make'), it must appear with a nominalizer. In the charts below, roots like this are represented by 'friend', as in (11). Some of these roots are considered traditional noun roots, while others are listed as deverbal nouns in some dictionaries.

(13) a. odi:

o-ti-:

[Cayuga]

NPREF-tea-NFS

'tea'

(Froman et al. 2002: 331)

b. edi?trǫnya?ta?

e-ti-?tra-ǫny-a-?t-a?

PREF-tea-NLZR-make-EPEN-CAUS-NFS

'teapot'

(Froman et al. 2002: 331)

The two Seneca examples in (14) and (15) illustrate the same asymmetry. The nominalizer is needed for incorporation, as shown in the (b) examples, but not for a full DP, as in the (a) examples.

(14) a. yeksá?ah

[Seneca]

ye-ksa-?ah

3sG.F-child-NFS

'girl'

${ }^{5}$ Thanks to an anonymous reviewer for raising this concern. 
b. yeksá?di:yo:h

ye-ksa-?t-iyo-h

3sG.F.AG-child-NLZR-be.good-STAT

'She's a good child.'

(Chafe 2014: 93)

(15) a. heya:de?

hey-atre-?

1sG.AG:3sG.M.PAT-grandchild-NFS

'my grandson'

b. agáde?shäga?de?

ak-atre-?shr-a-ka?te-?

1sG.AG-grandchild-NLZR-JOIN-be.many-STAT

'I have many grandchildren'

(Chafe 2014: 106)

Finally, the Oneida examples in (16) and (17) illustrate the same point.

(16) a. á:nuk ${ }^{6}$

[Oneida]

a-a?nuk- $\varnothing$

NPREF-Onion-NFS

'onion'

b. wa?akwa?nukslotúni?

wa?-a-kw-a?nuk-hsl-otuny-?

FACT-1PL.EXCL-onion-NLZR-stand.up-PUNC

'We stood up the onions planting them.

(Michelson and Doxtator 2002)

(17) a. atláhti?

a-atlahti-?

NPREF-SOck-NFS

'sock'

(Michelson and Doxtator 2002: 224)

b. $\Lambda$ shotlahti?tslay :táne?

$\Lambda$-s-ho-atlahti-?tsl-a-y $\mathrm{t}$-a-?-ne?

FUT-REP-3SG.M.PAT-SOck-NLZR-JOIN-lay.dow-EPEN-INCH-PUNC

'He will get (new) socks again.' $\quad$ (Michelson and Doxtator 2002: 224)

In summary, we see that the nominalizer is usually either absent in both noun incorporation and full DPs, or present in both structures. There are some cases where the nominalizer is present only in noun incorporation, but is not found on DPs. The converse, however, is not attested. There are no cases in which the nominalizer is present in DPs but absent in noun incorporation. In the next section we consider these properties in light of three recent proposals in the literature on the categorization of roots.

\footnotetext{
${ }^{6}$ Whether the nominal prefix is /a-/ or null is unclear since the initial /a/ of the base disappears when the preceding affix ends in a vowel.
} 


\section{PReVious analyses OF ROOTS AND CATEgORIES}

We begin with the traditional proposal that all roots are specified for lexical category (Chomsky 1970). We then discuss the Bare Root Hypothesis, which proposes that lexical roots are devoid of grammatical information, including categorial information (Borer 1984, 2005; Marantz 2001), and then move on to the Roots as Nouns Hypothesis (Kayne 2009).

First, let's consider a traditional analysis in which all roots are classified either as verbs or as nouns. Per Chafe (2012), adjectives are absent in Northern Iroquoian. Consider for a moment the selectional restrictions of verbs. It is clear they can take DPs as internal arguments. The fact that, at least some of the time, the internal argument requires an overt nominalizer strongly suggests that verbs require a complement that is labelled as nominal. ${ }^{7}$ Thus, we propose the following selectional restriction on verbs.

(18) Verbs select either DP or $n \mathrm{P}$ as a complement.

Under such an analysis, nominal roots require no nominalizer either for full DPs or for noun incorporation. Verbal roots require a nominalizer in both cases. Roots in the mixed category are more complicated, behaving like nouns when they appear in full DPs, and like verbs when they undergo noun incorporation. One could assume that such roots have two homophonous lexical entries (one noun and one verb), but such an ad hoc proposal does not explain why only the verbal form can be chosen for noun incorporation. Such a proposal overgenerates, allowing for the unattested pattern in which a nominalizer is found with full DPs but not with noun incorporation. One could also make an ad hoc proposal that certain nominal roots, for some reason, must take a null verbalizer before undergoing noun incorporation, thus requiring a nominalizer. Again, nothing would rule out a parallel situation, in which certain nominal roots take a null verbalizer when they appear in a full DP, thus requiring a nominalizer. In sum, assuming a traditional analysis in which all roots are categorially specified fails to explain the asymmetry described above. Tables 1 and 2 summarize these two proposals, respectively.

Next, we consider the Bare Root Hypothesis. According to Marantz (2001), all roots are bare and must eventually be categorized. When no overt categorizer is present, a null $n, v$, (or $a$ ) must be assumed. In Northern Iroquoian, what we traditionally call nominal roots would require a null $n$ both in full DPs and in noun incorporation, while what we traditionally call verbal roots would require an overt nominalizer in both environments. The mixed roots appear with a null $n$ in full DPs and with an overt NLZR in noun incorporation. However, nothing rules out the unattested pattern in which a bare root appears with an overt NLZR in a full DP and with a null $n$ in noun incorporation. Table 3 summarizes the arguments.

Finally, we consider the Roots as Noun Hypothesis (Kayne 2009). Kayne tentatively suggests that there may be no need for $n$, if all roots are categorially specified as N. Nevertheless, cross-linguistically we find many cases of overt

\footnotetext{
${ }^{7} \mathrm{We}$ are setting aside clausal complements for this discussion.
} 


\begin{tabular}{rccc}
\hline \hline Root & Category & full DP & Noun Incorporation \\
\hline tobacco & $\mathrm{N}$ & no $n$ & no $n$ \\
write & $\mathrm{V}$ & overt NLZR & overt NLZR \\
& & no $n$ & overt NLZR \\
friend & $\mathrm{N}$ and $\mathrm{V}$ & (N root selected) & (V root selected) \\
unattested & $\mathrm{N}$ and $\mathrm{V}$ & NLZR required & no $n$ \\
& & (V root selected) & (N root selected) \\
\hline \hline
\end{tabular}

Table 1. Categorial specifications in Northern Iroquoian assuming categorized homophonous roots

\begin{tabular}{rccc}
\hline \hline Root & Category & full DP & Noun Incorporation \\
\hline tobacco & $\mathrm{N}$ & no $n$ & no $n$ \\
write & $\mathrm{V}$ & overt NLZR & overt NLZR \\
friend & $\mathrm{N}$ & no $n$ & $v+$ overt NLZR \\
unattested & $\mathrm{N}$ & $v+$ overt NLZR & no $n$ \\
\hline \hline
\end{tabular}

Table 2. Categorial specifications in Northern Iroquoian assuming categorized roots and null verbalizer

\begin{tabular}{rccc}
\hline \hline Root & Category & full DP & Noun Incorporation \\
\hline tobacco & bare & null $n$ & null $n$ \\
write & bare & overt NLZR & overt NLZR \\
friend & bare & null $n$ & overt NLZR \\
unattested & bare & overt NLZR & null $n$ \\
\hline \hline
\end{tabular}

Table 3. Categorial specifications in Northern Iroquoian assuming bare roots

nominalizing morphology, including in Northern Iroquoian, as we have seen. Kayne recognizes that derived nouns exist (such as the removal of the evidence) and sketches a tentative proposal. He suggests that suffixal nominalizers may have the same analysis as the free-standing noun fact, namely that they are relative clauses (cf. the fact that the evidence was removed). ${ }^{8}$ The structure he suggests for removal of the evidence is given below. We have filled in the relevant functional projections based on his discussion, but we acknowledge that this is an extrapolation from his proposal.

\footnotetext{
${ }^{8}$ Constructions such as the fact that ... are traditionally thought of as a noun plus a clausal complement. Some researchers, including Kayne, have argued that nouns do not take complements and that such constructions should be re-analyzed as relative clauses.
} 
He proposes that the English nominalizer, $-a l$, is a nominal root, selected by a ghost $\mathrm{P}$. The PP $(\mathrm{P}-a l)$ modifies the $v \mathrm{P}^{9}$ and is followed by movement of the object the evidence for Case (to ZP), followed by merger of of. This step is not vital to the current discussion. The ghost PP then raises to the specifier of a higher functional projection (YP) and the $v \mathrm{P}$ undergoes remnant movement to the specifier of a yet higher functional projection (WP). Kayne specifically mentions the ghost PP, but does not mention the other unnamed functional projections, some of which could presumably be part of the extended nominal projection.

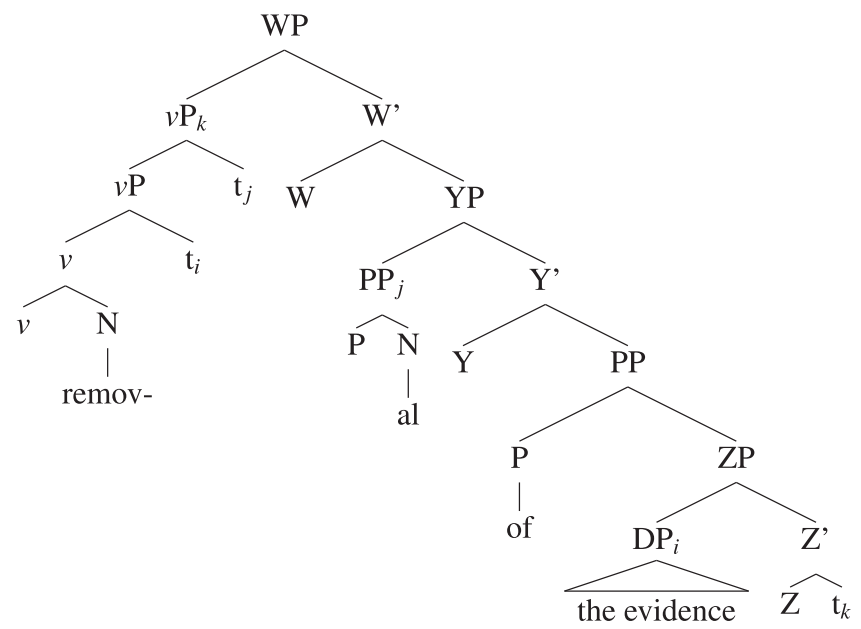

We note first that nominalized constructions in Northern Iroquoian are quite different from the removal-type constructions in English, so it is not clear that the analysis could be carried over easily. Crucially, in the English nominalizations the argument taking properties of the root are still present, while they are absent in Northern Iroquoian. Nevertheless, we examine how the Northern Iroquoian facts fare under a Kaynean analysis in which all roots are nouns.

Nouns have a straightforward explanation under the Roots as Nouns Hypothesis. Roots such as tobacco are simply N. As such, they require no nominalizer to form a full DP, nor do they need one in order to be incorporated.

Traditional verbal roots (the write-type) have two possible analyses under Kayne's approach. Kayne argues that verbs are largely derived by conflation of a noun with a $v$, in the sense of Hale and Keyser (2002). He also suggests that many verbs are quite likely light verbs rather than lexical verbs. In the conflation case, the root is composed of $\mathrm{N}+v$, and with light verbs, the root is composed of just $v$. Under this view, forms such as write in Northern Iroquoian would be simply a light verb $(v)$. Such forms would require a nominalizer either to form a DP or to be incorporated.

${ }^{9}$ This step of the derivation is clearly at odds with Antisymmetry, but it is well beyond the scope of this paper to fully articulate Kayne's proposal. One obvious suggestion is to place the complement of the verb (the evidence) and the PP (P -al) in a Larsonian VP shell. 
The curious case is forms such as friend. Recall that such forms require a nominalizer only if they undergo NI. If we assume that such forms are obligatorily $v+\mathrm{N}$, leaving aside the question of how to ensure that the $\mathrm{N}$ root friend obligatorily merges with $v$ before undergoing further derivation, we have a possible explanation for the facts. Noun incorporation boils down to selection as in (18). The structure $v+\mathrm{N}$ requires a nominalizer in order to be selected by a verb. However, the full DP is more difficult to account for. We would have to assume that $v$ is somehow invisible for the purposes of forming a full DP with friend-type roots but not with write-type roots. The relevant forms are repeated in (20), and the putative trees under the Roots as Nouns Hypothesis are shown in (21).

(20) a. egátci?

yǫk-atci-?

1DU.PAT-friend-NFS

'my friend'

[Onondaga]

b. hatsihsá:yęk

ha-atci-hsR-a-yę-k

3sG.M.AG-friend-NLZR-JOIN-know.how-HAB

'He knows how to be friends.'

(Woodbury 2003: 255)

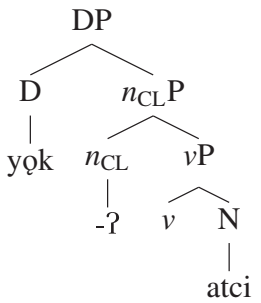

b.

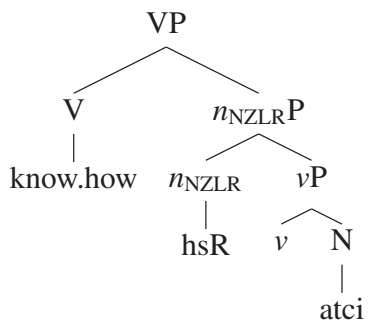

Kayne's analysis does, however, offer an account of why the unattested category does not surface. The three kinds of roots in Northern Iroquoian are $\mathrm{N}, v$, and $v+\mathrm{N}$, respectively. There is no conceivable way of forming the fourth, unattested type. However, it is unclear why the $\mathrm{N}$ root in the friend-type constructions cannot be incorporated independently of $v$, as it is already nominal. One would have to say that certain $\mathrm{N}$ roots are lexically encoded as requiring a $v$ before undergoing further operations. The following table summarizes these conclusions.

The Roots as Nouns Hypothesis does rule out the unattested pattern. Crucially, the only three possible patterns are $\mathrm{N}, \mathrm{N}+v$, and $v$. $\mathrm{N}$ roots, such as tobacco, do not require a nominalizer either to form full DPs or to undergo NI, as expected. The $v$ 


\begin{tabular}{rccc}
\hline \hline Root & Category & full DP & Noun Incorporation \\
\hline tobacco & $\mathrm{N}$ & $\varnothing$ & $\emptyset$ \\
write & $v$ & overt NLZR $(=\mathrm{P}+\mathrm{N})$ & overt NLZR $(=\mathrm{P}+\mathrm{N})$ \\
friend & $\mathrm{N}+v$ & $\emptyset$ & overt NLZR $(=\mathrm{P}+\mathrm{N})$ \\
unattested & $? ? ?$ & overt NLZR $(=\mathrm{P}+\mathrm{N})$ & null $n$ or $\varnothing$ \\
\hline \hline
\end{tabular}

Table 4. Categorial specifications in Northern Iroquoian assuming $\mathrm{N}$ roots

forms, such as write, require a nominalizer in both cases, as expected. What is left unexplained is why the $\mathrm{N}+v$ forms, such as friend, require $v$.

To summarize, we have examined three proposals for the nature of roots and lexical categories, and we have shown that all three are unable to explain the facts regarding nominalizers in Northern Iroquoian. Crucially, the first two proposals, the traditional approach in which roots are categorized and the Bare Roots Hypothesis overgenerate, producing the unattested pattern. The Roots as Nouns Hypothesis captures the three categories observed, but does so at the expense of having to stipulate that certain roots (e.g., friend) must merge with $v$ before undergoing further derivation. Also unexplained is why no nominalizer is needed in order for the $v \mathrm{P}$ in (21a) to participate in DP formation. We now turn to our proposal, which generates the observed pattern without overgenerating the unattested pattern, and does so with fewer stipulations than the Roots as Nouns Hypothesis.

\section{Proposed analysis}

Section 2 outlined the important details of nominal and verbal structure in Northern Iroquoian and discussed an asymmetry in the behaviour of some roots in the formation of DPs and noun incorporation. In the previous section, we analysed this asymmetry using three well known hypotheses on lexical categories and all were shown to be problematic.

\subsection{Nominal structure}

An important part of our analysis relies on the fact that the noun class suffix (NFS) appears outside the nominalizer, as can be seen in (10b) above, repeated here as (22).

(22) hodaiditsheda?

ho-at-a?ti-tshR-ot-a?

3SG.M.PAT-SRFL-lean-NZRL-stand.upright/have-STAT

'He is using a cane.'

(Woodbury 2003: 102)

Following the Mirror Principle (Baker 1988), we deduce that the nominalizing head (NLZR) is structurally lower than the noun class suffix head (NFS, which we call $\left.n_{\mathrm{CL}}\right)$. Thus, we assume an extended nominal projection in the sense of Grimshaw (1990) with a partial structure as in (23). We assume that the nominal prefix heads a functional projection somewhere between DP and $n_{\mathrm{CL}} \mathrm{P}$, but its exact 
location does not impinge on the current discussion. For convenience, we show the nominal prefix in $\mathrm{D}$ in the derivations below, but leave the exact location to future research.

$$
\mathrm{DP}>\ldots>n_{\mathrm{CL}} \mathrm{P}>n_{\text {nlzr }} \mathrm{P}>\text { root }
$$

Recall from (18) above that we assumed that the complement to the verb must be nominal, clausal complements notwithstanding. In order to make the proposed analysis work, one more assumption is needed:

(24) A full DP contains a $n_{\mathrm{CL}}$, which selects a categorized complement.

This assumption requires some discussion and builds on the observation that full DPs require a nominalizer some of the time in the Northern Iroquoian data discussed here. Observe in the following English examples that some categorizing morphology can appear with a bare root. ${ }^{10}$

(25) a. mechan-ic; mechan-ism; mechan-ize

b. calcul-ate; calcul-able

Some affixes, however, can attach only to certain categories (Fabb 1988). For instance, -ness attaches only to adjectives and -less attaches only to nouns. Some categorizers, thus, select either $a$ or $n$, rather than a bare root. It is not unreasonable, then, to propose that $n_{\mathrm{CL}}$ requires a lexical category as a complement. In other words, $n_{\mathrm{CL}}$ selects either something nominal or something verbal, but not a bare root. We will return to the exact specification of the selectional restriction of $n_{\mathrm{CL}}$. For the moment, we propose that Northern Iroquoian $n_{\mathrm{CL}}$ requires either a nominal or a verbal complement.

Evidence that a verbal complement is possible in DPs comes from examples like (26). The morpheme kli is a verbal root and can appear as a noun without the benefit of a nominalizer. ${ }^{11}$

(26) ohnekákeli?

o-hnek-a-kli-?

NPREF-liquid/liquor-JoIN-be.a.liquid-NFS

'broth, watery soup'

[Oneida]

Such forms can also be verbs. In (27), the Onondaga light verb ki: is shown, which is cognate with Oneida kli.

(27) ohyá:gi:?

o-ahy-a-ki:-?

[Onondaga]

\footnotetext{
${ }^{10} \mathrm{~A}$ reviewer questions whether the root of mechanic is simply machine and that mechan- is an allomorph of machine. This is possible; however, there are also forms such as Cyrillic which is historically based on Cyril; however, not all speakers are aware of this historical fact or even know who St. Cyril is. For such speakers, we assume that Cyrillic has a bound root.

${ }^{11} \mathrm{~A}$ reviewer asks for evidence that $\mathrm{kli} / \mathrm{ki}$ : is a verbal root. The fact that it can incorporate nouns strongly suggests that it is a traditional verb root, as only traditional verbal roots can host incorporated nouns in Northern Iroquoian. Noun-noun compounds do not occur in these languages.
} 
3SG.NT.PAT-fruit-JOIN-be.a.liquid-STAT

'It is apple juice.'/'It is fruit juice.'

A nominalizer, however, is required in order to incorporate the complex noun in (26) into a larger verbal complex.

(28) wakathnekakli?tsluní

[Oneida]

wak-at-hnekakli-?tsl-uni-'

1SG.PAT-SRFL-broth-NLZR-make-STAT

'I have made soup.'

(Michelson and Doxtator 2002: 388)

With this background we now present the proposal for the categorial specification of roots in Northern Iroquoian.

\subsection{Categorial specification of roots}

The above facts fall into place if we assume that some roots are pre-specified as nouns, some roots are pre-specified as verbs, and some roots are truly acategorial. A large subset of Northern Iroquoian roots are pre-specified as nouns (the tobaccotype). As such, they do not require a nominalizer either for full DPs or for noun incorporation. Another large subset of Northern Iroquoian roots are acategorial (the write-type). Such roots require a nominalizer both for full DPs and for noun incorporation. Finally, a small number of roots are pre-specified as verbs (the friend-type). This small class of roots requires a nominalizer only for noun incorporation since the $n_{\mathrm{CL}}$ in full DPs can be satisfied by a verbal complement. Table 5 summarizes these three situations.

While the categorial specifications in Table 5 derive the properties of the nominalizer discussed here, the result is somewhat unexpected. Specifically, the root meaning 'friend' is classified as a verb. Aside from the properties related to the nominalizers, the categories proposed here exhibit some traditional morphosyntactic differentiation. As Mithun (2000) makes clear, and as is clear from the discussion throughout this article, the categories of $\mathrm{N}$ and root have clear morphological differences. What is less clear is whether there is a difference between category $\mathrm{V}$ and category N, as a reviewer points out. Roots in both these classes are traditional nouns. Koenig and Michelson (2010) discuss the exceptional nature of kinship terms in Oneida, noting one property they have is that they require the nominalizer for incorporation, but not for appearing as a full DP. We leave for future research how to reconcile the facts in Koenig and Michelson (2010) with the proposal here. The same reviewer asks how roots are identified in Northern Iroquoian and how they

\begin{tabular}{rccc}
\hline \hline Root & Category & full DP & Noun Incorporation \\
\hline tobacco & $\mathrm{N}$ & no NLZR & no NLZR \\
friend & $\mathrm{V}$ & no NLZR & NLZR required \\
write & acategorial & NLZR required & NLZR required \\
\hline \hline
\end{tabular}

Table 5. Categorial specifications in Northern Iroquoian 
relate to the ontological notions of roots. Baker (2003) gives an excellent overview of the history of the linguistic theorizing of lexical categories. He reminds us that ontological distinctions do not provide a reliable foundation for understanding lexical categories. Pairs such as destroy and destruction both refer to the same concept, but one is expressed as a verb and the other as a noun. Some nouns such as party refer to an event and some verbs such as know do not. The reader is invited to consult Baker and the references cited therein for a full discussion.

We follow the structuralist tradition of ascertaining the category of a linguistic object (in this case the root) by examining the morphosyntactic frames in which it can be found. For instance, nouns can appear with plural morphology and verbs can appear with aspectual morphology. Baker (2003) gives an excellent discussion of the difference between verbs and nouns in Mohawk; however, since his goal is to give a general cross-linguistic framework in which to understand lexical categories, he does not discuss the friend-type roots. In the same spirit, then, we take the behaviour of the nominalizer as a further morphosyntactic diagnostic of lexical category.

\subsection{Derivation of DPs}

Recall that the extended nominal projection includes a $n_{\mathrm{CL}} \mathrm{P}$, and that $n_{\mathrm{CL}}$ selects a categorized complement, following the structure sketched in (24). Thus, a nominalizer is required only for acategorial roots. We illustrate here the derivation of a DP based on each of the three types of roots we proposed. First, we illustrate the derivation of a DP formed from an $\mathrm{N}$ root. This represents a prototypical noun in Northern Iroquoian. Consider (29a), repeated from (6) above, and its derivation in (29b). We assume head movement for simplicity, although the structures below could be made consistent with an XP movement account along the lines of Barrie and Mathieu (2016). We therefore believe that the question of head movement versus XP movement does not affect the arguments put forward here.

(29) a. oyę́kwa?

o-yękw-a?

NPREF-tobacco-NFS

'tobacco'

b.

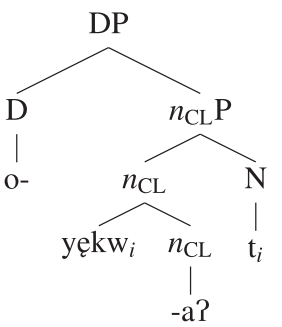

Next consider a DP formed from a V root. The Onondaga example in (30), repeated from (11), shows the derivation for 'my friend'. 
(30) a. Qgátci?

[Onondaga]

yǫk-atci-?

1DU.PAT-friend-NFS

'my friend' / 'We two are friends.'

(Woodbury 2003: 255)

b.

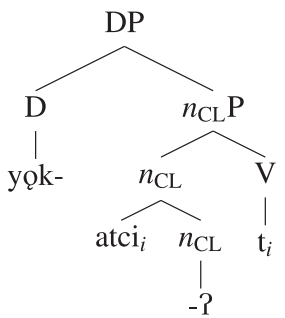

Finally, consider a DP formed from bare root. Since the root is not categorized, a nominalizer is necessary to make a well-formed DP. This is shown in the Cayuga example in (31), repeated from (9b).

(31) a. gahyádohsra?

ka-hyatǫ-hsr-a?

NPREF-write-NLZR-NFS

'paper'

[Cayuga]

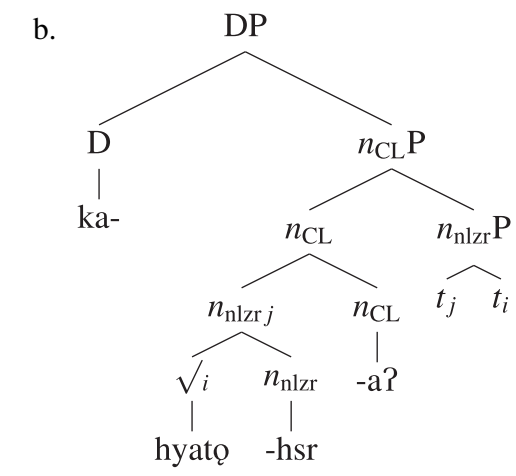

(Froman et al. 2002: 224)

\subsection{Derivation of noun incorporation}

Next we consider the derivation of noun incorporation. Recall that in Northern Iroquoian, noun incorporation is typically formed by the incorporation of a nominal root into the verbal complex. The nominalizer is present only when the incorporated root is not pre-specified as nominal, as predicted by the assumption that verbs select a nominal complement. Consider the Onondaga example in (32a), repeated from (6). The structure of the tree before movement operations is shown in (32b). Since $y e k w$ is pre-specified as $\mathrm{N}$, no nominalizer appears.

(32) a. wa?-ha-yękw-a-hninu-?

[Onondaga]

FACT-3SG.M.AG-tobacco-JOIN-buy-PUNC

'He bought tobacco.' 
b.

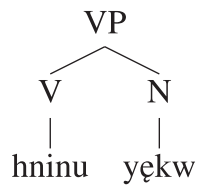

The nominalizer is needed in order to incorporate $\mathrm{V}$ roots. Crucially, these are the roots that do not require a nominalizer to form full DPs. An example of this sort is shown in (33), repeated from (11).

(33) a. hatsihsắ:yęk ha-atci-hsR-a-yę-k

[Onondaga]

3SG.M.AG-friend-NLZR-JOIN-know.how-HAB

'He knows how to be friends.'

(Woodbury 2003: 255)

b.

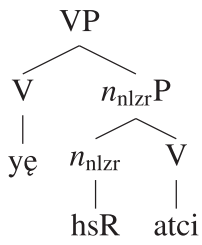

Finally, the nominalizer is needed in order to incorporate bare roots, since verbs require a nominal complement. An example of this is given in (34).

(34) syadǫhsraędi?

s-hyatọ-hsr-yętei-?

[Cayuga]

2SG.AG-write-NLZR-know-HAB

'You are smart.'

('know-paper' is an idiom for 'be smart')

(Dyck et al. 2014: 484)

The tree in (35) shows the pre-movement structure for (34). The verb selects a nominal complement, which subsequently undergoes incorporation. Thus, in all three cases, the verb selects something nominal, either $n \mathrm{P}$ or $\mathrm{N}$.

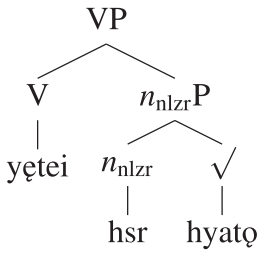

\subsection{Derivation of verbs}

In this section we extend the analysis of roots to give a preliminary analysis of verbal constructions. So far, we have considered the role of nominalizers in the formation of full DPs and in noun incorporation. We have not considered the extended verbal projection. As we have seen above, $\mathrm{V}$ roots and bare roots form verbs without the benefit of categorizers. One may wonder why bare roots do not need a $v$ along the lines of Marantz. Borer (2005) suggests that categorial information can be gleaned by higher inflectional morphology. Thus, the higher functional projections such as aspect, agreement, and mood provide enough information to signal that the construction in question 
is a verb. Recall that the nominalizer was used not to give categorial information, but rather to satisfy selectional restrictions.

Traditionally, Northern Iroquoian languages are not described as having verbalizers (in comparison to the nominalizers described above, which are well documented in the traditional Iroquoian literature). However, there is a small class of forms with properties that are similar to those of light verbs. In particular, these light verbs require noun incorporation, akin to what Johns (2007) describes for Inuktitut. Consider (36), as well as (26) above.

(36) oye?gw-e:da?

[Onondaga]

o-ye?kwR-ot-a?

3SG.N.PAT-smoke-stand.upright-STAT

'Smoke is rising.'

(Barrie 2015: ex. (128))

Unlike the nominalizer, which is purely grammatical, these light verbs do carry some meaning. Given the analysis we proposed above, we make the following observations about verbal structures. $\mathrm{N}$ roots cannot appear as verbs, unless a light verb is present as in (36). $\mathrm{V}$ roots and bare roots can appear as verbs without any special morphology. Thus, true verbalizers are needed only to form a verbal structure from a lexical noun.

\section{CONCLUSION}

We have examined the distribution of the nominalizer in Northern Iroquoian in light of current proposals on the categorial identity of roots. Specifically, we have examined (i) the traditional approach to roots, in which all roots are categorized as nouns or verbs (adjectives are absent in Northern Iroquoian), (ii) the Bare Root Hypothesis of Borer and Marantz, in which all roots lack categorial identity, and (iii) the Roots as Noun Hypothesis of Kayne, in which all roots are nouns. We have shown that the distribution of the overt nominalizer in full DPs and in noun incorporation constructions in Northern Iroquoian is problematic for all three of these hypotheses. Instead, we have proposed that some roots are categorially specified as either nouns or verbs, while others truly are bare. Minimal and fairly standard assumptions were made to account for the distribution of the nominalizer under our proposal.

Our investigation still leaves us with an interesting asymmetry. The majority of roots in Northern Iroquoian are either $\mathrm{N}$ roots or bare. Only a small handful are $\mathrm{V}$ roots. This accords loosely with Kayne's conclusion that only nouns represent an open class. Verbs, on the other hand are either functional or are formed from a nominal root combined with a light verb. We leave the typological implications of this conclusion to future research.

One final issue we leave unresolved is how borrowed roots fit into the system we discussed. Recall examples (12) and (13) above, which contain borrowed roots. In both of these cases the borrowed roots behaved like other roots in that they both appear with regular nominal morphology. We argued there that such roots have become nativized into their respective languages (as restaurant and wine have become nativized into English) and thus behave no differently from native roots. 
However, consider the examples in (37) and (38), the first from Cayuga and the second from Oneida.

(37) gajobtri:yo

ka-job-tr-iyo- $\varnothing /$

[Cayuga]

3SG.NT.AG-job-NLZR-be.good-STAT

'a good job'

(Dyck et al. 2014)

(38) a. khófe

'coffee'

[Oneida]

b. wa?kekhofe?stlahnekí:la?

wa?-k-khofe-?stl-a-hnekihl-a?

FACT-1SG.AG-coffee-NLZR-JOIN-drink-PUNC

'I drank coffee.'

(Michelson and Doxtator 2002: 481)

Borrowed nouns generally require a nominalizer in order to be incorporated, as we saw in (12) and (13) above, but in (38a) the full, stand-alone DP khófe does not require a nominalizer. Note, however, that all DP morphology is absent in the case of 'coffee'. While the fact that an overt NLZR is required only for incorporation aligns with the observations in this study, the morphological implications await future research.

\section{REFERENCES}

Abbott, Clifford. 2000. Oneida. Munich: Lincom Europa.

Baker, Mark C. 1985. The mirror principle and morphosyntactic explanation. Linguistic Inquiry 16(3): 373-416.

Baker, Mark C. 1988. Incorporation: A theory of grammatical function changing. Chicago: University of Chicago Press.

Baker, Mark C. 1996. The polysynthesis parameter. Oxford: Oxford University Press.

Baker, Mark C. 2003. Lexical categories. Cambridge: Cambridge University Press.

Barrie, Michael. 2015. A grammar of Onondaga. Berlin: Lincom.

Barrie, Michael, and Eric Mathieu. 2016. Noun incorporation and phrasal movement. Natural Language and Linguistic Theory 34(1): 1-51.

Borer, Hagit. 1984. Parametric syntax: Case studies in Semitic and Romance languages. Studies in Generative Grammar. Dordrecht: Foris Publications.

Borer, Hagit. 2005. Structuring sense: Volume 1: In name only. Oxford: Oxford University Press.

Caramazza, Alfonso, and Kevin Shapiro. 2004. Language categories in the brain: Evidence from aphasia, 15-38. Oxford: Oxford University Press.

Chafe, Wallace. 2012. Are adjectives universal? The case of Northern Iroquoian. Linguistic Typology 16(1): 1-39.

Chafe, Wallace. 2014. A grammar of the Seneca language. Oakland: University of California Press.

Chomsky, Noam. 1970. Remarks on nominalization. In Readings in English transformational grammar, ed. Roderick Jacobs and Peter Rosenbaum, 184-221. Waltham, MA: Ginn.

Chomsky, Noam, and Howard Lasnik. 1977. Filters and control. Linguistic Inquiry 8(3): 425-504. 
Chung, Sandra. 2012. Are lexical categories universal? The view from Chamorro. Theoretical Linguistics 38(1-2): 1-56. doi: 10.1515/tl-2012-0001.

Compton, Richard. 2013. Word-internal XPs and right-headedness in Inuit. Paper presented at WCCFL 31, Arizona State University.

Dyck, Carrie, Frances Froman, Alfred J. Keye, and Lottie Keye. 2014. LIN 6050 - Structure of Cayuga: Course package. Memorial University of Newfoundland and Woodland Cultural Centre.

Fabb, Nigel. 1988. English suffixation is constrained only by selectional restrictions. Natural Language and Linguistic Theory 6: 527-539.

Froman, Frances, Alfred J. Keye, Lottie Keye, and Carrie Dyck. 2002. English-Cayuga/ Cayuga-English dictionary. Toronto: University of Toronto Press.

Grimshaw, Jane. 1990. Argument structure. Cambridge, MA: MIT Press.

Hale, Kenneth, and Samuel Jay Keyser. 2002. Prolegomenon to a theory of argument structure. Cambridge, MA: MIT Press.

Harley, Heidi. 2009. Compounding in Distributed Morphology. In The Oxford Handbook of Compounding, ed. Rochelle Lieber and Pavol Štekauer, 129-144. Oxford: Oxford University Press.

Haugen, Jason D., and Daniel Siddiqi. 2013. Roots and the derivation. Linguistic Inquiry 44 (3): 493-517. doi: 10.1162/LING_a_00136.

Johns, Alana. 2007. Restricting noun incorporation: root movement. Natural Language and Linguistic Theory 25(3): 535-576.

Julian, Charles. 2010. A History of the Iroquoian Languages. Ph.D. Dissertation, University of Manitoba.

Kayne, Richard. 2009. Antisymmetry and the lexicon. Linguistic Variation Yearbook 8(1): $1-31$.

Koenig, Jean-Pierre, and Karin Michelson. 2010. Argument structure of Oneida kinship terms. International Journal of American Linguistics 76(2): 169-205.

Lounsbury, Floyd G. 1949. Iroquoian morphology. Doctoral dissertation, Yale University.

Lounsbury, Floyd G. 1953. Oneida verb morphology. New Haven, CT: Yale University Press.

Marantz, Alec. 1997. No escape from syntax: Don't try morphological analysis in the privacy of your own lexicon. University of Pennsylvania Working Papers in Linguistics 4(2): 201-225.

Marantz, Alec. 2001. Words. Paper presented at the 20th West Coast Conference on Formal Linguistics, University of Southern California.

Michelson, Karin. 2016. Iroquoian languages. Oxford Bibliographies Online. Oxford: Oxford University Press. doi: 10.1093/OBO/9780199772810-0023.

Michelson, Karin, and Mercy Doxtator. 2002. Oneida-English/English-Oneida dictionary. Toronto: University of Toronto Press.

Michelson, Karin, Norma Kennedy, and Mercy Doxtator. 2016. Glimpses of Oneida life. Toronto: University of Toronto Press.

Mithun, Marianne. 1979. Iroquoian. In The languages of Native America: A historical and comparative assessment, ed. Lyle Campbell and Marianne Mithun, 133-212. Austin: University of Texas Press.

Mithun, Marianne. 1984. The evolution of noun incorporation. Language 60(4): 847-894.

Mithun, Marianne. 2000. Noun and verb in Iroquoian languages: Multicategorisation from multiple criteria. In Approaches to the typology of word classes, ed. Petra M. Vogel and Bernard Comrie, 397-420. Berlin: Mouton de Gruyter.

Mithun, Marianne, and Reginald Henry. 1984. Wadęwayéstanih: A Cayuga teaching grammar. Brantford, ON: Woodland Cultural Center. 
Moulton, Keir. 2014. Simple event nominalizations: Roots and their interpretation. In Crosslinguistic investigations of nominalization patterns, ed. Ileana Paul, 119-144. Amsterdam: John Benjamins.

Panagiotidis, E. Phoevos. 2011. Categorial features and categorizers. The Linguistic Review 28(3): 365-386. doi: 10.1515/tlir.2011.010.

Sato, Yosuke. 2010. Complex phrase structures within morphological words: Evidence from English and Indonesian. Lingua 120(2): 379-407.

Wiltschko, Martina. 2005. The syntax of precategorial roots. In Proceedings of the Tenth Workshop on Structure and Constituency in Languages of the Americas, ed. Solveiga Armoskaite and James J. Thompson. Vancouver: University of British Columbia Working Papers in Linguistics.

Woodbury, Hanni. 1975a. Noun incorporation in Onondaga. Doctoral dissertation, Yale University.

Woodbury, Hanni. 1975b. Onondaga noun incorporation: Some notes on the interdependence of syntax and semantics. International Journal of American Linguistics 41(1): 10-20.

Woodbury, Hanni. 2003. Onondaga-English/English-Onondaga dictionary. Toronto: University of Toronto Press.

Woodbury, Hanni. 2018. A reference grammar of the Onondaga language. Toronto: University of Toronto Press. 